ISSN: 0213-2060

DOI: http://dx.doi.org/10.14201/shhme201432161185

\title{
LAS FUENTES EN JUAN DE BICLARO*
}

\author{
The sources of John of Biclarum
}

\begin{abstract}
Mikel POZO FLORES
Depto. de Historia Medieval, Moderna y de América. Facultad de Letras. Universidad del País Vasco-Euskal Herriko Unibertsitatea. Paseo de la Universidad, 5. E-01006VITORIA-GASTEIZ. C. e.: mikel.pozo@ ehu.es
\end{abstract}

Recibido: 2012-12-30

Revisado: 2013-07-01

Aceptado: 2013-09-20

BIBLID [0213-2060(2014)32;161-185]

RESUMEN: A pesar de que las investigaciones de los últimos años han puesto en evidencia que Juan de Biclaro construyó su Crónica según un plan preciso y al servicio de un determinado discurso político, en lo que se refiere al tratamiento de sus fuentes se mantiene una inercia que hace de Juan una especie de testigo bienintencionado cuya información provendría de manera mayoritaria de su propia vivencia y de testimonios directos. Sin embargo, se puede sostener que el Biclarense no solo empleó sofisticadamente materiales de los historiadores bizantinos, sino que pudo tener en cuenta los Decem Libri Historiarum de Gregorio de Tours para proponer una lectura alternativa de la rebelión de Hermenegildo destinada a sostener la legitimidad de la monarquía católica y del linaje real. El examen coherente del discurso político y de la práctica del Biclarense permite, en fin, sugerir que la horquilla cronológica de la composición y publicación de la Crónica debiera extenderse quizás hasta el reinado de Sisebuto.

Palabras clave: Juan de Biclaro. Crónica. Historiografía tardoantigua. Historiadores bizantinos. Gregorio de Tours. Reino visigodo.

* Beca predoctoral para la Formación de Investigadores del Gobierno Vasco. Este trabajo forma parte de investigaciones financiadas por el MINECO (HAR2010-20763) y por el DEUI del Gobierno Vasco (IT536-19) (UFI 11/02). 
ABSTRACT: Although recent studies have shown that John of Biclarum built his Chronicle following a precise plan and at the service of a specific political discourse, as far as the treatment of his sources is concerned scholars maintain a certain inertia which tends to make of him a sort of well-intentioned witness, whose information would have mostly come from his own experience and direct testimonies. However, it is possible to maintain not only that John of Biclarum used in a sophisticated way materials produced by Byzantine historians, but also that he could rely on Gregory of Tours's Decem Libri Historiarum so as to propose an alternative reading of Hermenegild's rebellion meant to sustain the legitimacy of the catholic monarchy and of the royal lineage. Finally, a coherent analysis of John's political discourse and practice also permits to suggest that the chronological frame of the Chronicle's composition and publication should be extended, possibly including Sisebut's reign.

Keywords: John of Biclarum. Chronicle. Late antique historiography. Byzantine historians. Gregory of Tours. Visigothic kingdom.

SUMARIO: 0 Introducción. 1 ¿Primacía de las fuentes orales? 2 Uso y descontextualización de las fuentes griegas. 3 El probable diálogo con las Historias de Gregorio de Tours. 4 Construcción de la Crónica y contexto político e intelectual. 5 Conclusiones.

\section{INTRODUCCIÓN}

Antes de las investigaciones de las dos últimas décadas, era opinión común que Juan de Biclaro escribió su Crónica como ferviente católico, sí, pero también como testigo bienintencionado de los reinados de Leovigildo y Recaredo. Prueba de ello sería su tratamiento de la rebelión de Hermenegildo, más atento a la legitimidad de la Corona que a la militancia religiosa que comparten cronista y rebelde. Este punto de vista explica un contraste llamativo entre la talla intelectual atribuida al Biclarense y la manera en que se concibe su práctica como cronista: ya J. Campos hizo hincapié en la formación de primer orden que el Biclarense recibió en Constantinopla ${ }^{1}$ y en los eruditos, incluidos historiadores, que debió conocer en la capital, pero desligó luego esta educación del utillaje del que se valió Juan para componer su Crónica ${ }^{2}$. Otros autores se han limitado a aludir a la estancia en Constantinopla ${ }^{3}$. Se pensaba que Juan había recogido lo esencial de la información de sus propias experiencias y de las de testigos directos, siendo excepcional el uso de fuentes escritas. Al menos desde E. Flórez y luego con el respaldo inmenso de

1 [...] cum esset adolescens, Constantinopolim perrexit, ibique graeca et latina eruditione nutritus, septimo demum anno in Hispanias reuersus est. Isid. Hisp. De Vir. Illustr., XVI (Codoñer, C. (ed.). El "De Viris Illustribus» de Isidoro de Sevilla: estudio y edición crítica. Salamanca, 1964). En esta edición se solventó el error que situaba a Juan en Constantinopla durante diecisiete ańos. Este hecho es relevante, ya que Campos, J. Juan de Biclaro, obispo de Gerona. Su vida y su obra. Madrid, 1960, p. 18, no conocía la corrección de Codoñer.

2 Campos, Juan de Biclaro, pp. 17-20.

3 Galán, P. J. El género historiográfico de la chronica. Las crónicas hispanas de época visigoda. Cáceres, 1994, p. 82; Cardelle, C. (ed.). Victoris Tunnunensis Chronicon cum reliquiis ex Consularibus Caesaraugustanis et Iohannis Biclarensis Chronicon. Turnhout, 2001 p. 125*. 
Th. Mommsen ${ }^{4}$, la desigual distribución en el tiempo de las noticias relativas al reino visigodo y al Imperio no sería sino el reflejo de la trayectoria vital del autor, es decir, de su juventud en Constantinopla y de su madurez en Hispania.

Los estudios de P. J. Galán y F. M. Fernández Jiménez han mostrado que tal asimetría -mayoría de noticias del Imperio al principio y mayoría de pasajes relativos a Hispania al final- tiene poco de espontánea: el número total de entradas correspondientes a cada espacio político es idéntico 5 , de tal manera que de las 93 noticias que componen la Crónica, 45 informan sobre hechos relacionados con cada una de las dos entidades políticas y las tres restantes se refieren a los inicios de los pontificados de Benedicto I, Pelagio II y Gregorio Magno. Hay un plan previo que Fernández Jiménez ha puesto en evidencia y que engrana en la estructura de la Crónica la imagen de un Imperio cuya franca decadencia realza el auge del reino visigodo ${ }^{6}$. Los soberanos de este último no sufren jamás una derrota, frente a las dificultades que tienen los emperadores para frenar el retroceso de sus fronteras ${ }^{7}$.

Estos nuevos enfoques han supuesto un cambio profundo en la valoración histórica de la Crónica del Biclarense. Sin embargo, en lo que se refiere al tratamiento de sus fuentes por Juan de Biclaro, no han acabado de sacudir una cierta inercia derivada de los puntos de vista tradicionales, a pesar de que ello genera incoherencias en la comprensión global de la obra. En nuestra opinión, una de las virtudes de estos nuevos enfoques es que pueden y deben suscitar nuevos interrogantes.

\section{1 ¿PRIMACÍA DE LAS FUENTES ORALES?}

Una primera cuestión se refiere al peso de las fuentes orales en la Crónica, que sigue siendo considerada como decisiva por varios especialistas. El problema es que el argumento fundamental es una afirmación del propio Juan, según la cual él habría recogido tanto hechos que vio con sus propios ojos, como episodios de los que supo por relatos dignos de crédito ${ }^{8}$. La duda que se plantea es clara: una vez que ha quedado establecido que el Biclarense estructura su Crónica en función de un discurso político y que estamos ante alguien que ha aprendido en Constantinopla las reglas del género cronístico, ¿̇debemos tomar esta afirmación como una descripción inocente de su práctica? No en vano, la alusión a testigos o a la propia experiencia es un tópico bien conocido de la historiografía

4 Flórez, E. España Sagrada. Madrid, 1859 [1750¹], vol. VI, p. 362; Mommsen, T. (ed.). MGH, AA, XI, Berlin, 1894, p. 208.

5 Galán, El género historiográfico, p. 124; Fernández Jiménez, F. M. «El Chronicon de Juan de Bíclaro. La crónica del rey Leovigildo y del III Concilio de Toledo. Estudio y traducción». Toletana, 2007, vol. 16, pp. 34-35. De todos modos, ambos autores admiten que algo hay de la experiencia vital del Biclarense en la estructura de la obra.

6 Fernández Jiménez, «El Chronicon», pp. 34-35.

7 Ibidem, p. 36.

8 [...] ex parte quod occulata fide preuidimus et ex parte que ex relatu fidelium didicimus (IoHAN. BICL, Chron., Praef: Cardelle (ed.), Victoris Tunnunensis). 
antigua y medieval ${ }^{9}$. A título de ejemplo, Procopio, que había recibido una formación no esencialmente distinta de la de Juan, alude al mismo en Los edificios (VI 7.18), publicado hacia $561^{10}$. Luciano de Samosata (c 120-192) critica que los historiadores no usen con el debido cuidado la figura del testigo y que digan haber presenciado hechos cuando no es cierto $^{11}$. En el otro extremo de la cristiandad, Beda introducirá a testigos, reales o no, que a ojos del lector daban una mayor credibilidad al relato: en ocasiones mantiene el nombre del testigo citado por su fuente, en otras lo cambia o directamente lo suprime ${ }^{12}$.

Naturalmente, no puede llevarse al extremo la precaución frente al tópico y negar que hay hechos en la Crónica presenciados por el autor. Ningún problema hay en que, por ejemplo, en relación a la peste en la capital imperial, Juan utilice vidimus para presentarse como el testigo que muy probablemente fue. Tan es así que es a partir de los verbos en primera persona como Galán ha ubicado entre 570 y 578 el tiempo de la estancia de Juan en Constantinopla ${ }^{13}$. Pero de ahí a pensar que un recurso retórico habitual de los historiadores de la época es en Juan de Biclaro una manifestación de imparcialidad, hay un trecho que no nos parece justificado recorrer y que se compadece mal, por ejemplo, con la misma concepción providencialista de la obra ${ }^{14}$.

A favor de la primacía de los testimonios orales se ha aducido también un razonamiento relativo a ciertas formas onomásticas y toponímicas de la Crónica. Según C. Cardelle, el que Juan escribiera Aluinus, Sisiuerti y Hodierno, en lugar de Alboinus, Sigisberti y Ugernum, pondría en evidencia el uso de informaciones verbales: la incorrección ortográfica se explicaría precisamente porque Juan escribiría según le sonaban en la pronunciación del latín de la época ${ }^{15}$. Pero, para que tal argumento sea convincente, es preciso que estos nombres tengan una forma escrita bien fijada de la que Juan se desviaría, lo que no es en absoluto evidente. Es cierto que Gregorio de Tours y Mario de Avenches escriben el nombre del rey lombardo como Alboenus o Alboinus $^{16}$, pero hay variantes bien distintas en las obras de otros historiadores que el Biclarense conoce. Menandro Protector, que escribe en la segunda mitad del siglo vi y es por tanto coetáneo de Alboino, se refiere a este

9 Marincola, J. Authority and Tradition in Ancient Historiography. Cambridge, 1997, pp. 5 y $63-$ 86; Sánchez Salor, E. Historiografía latino-cristiana: principios, contenido, forma. Roma, 2006, pp. 66 y ss. El propio GaLÁN, El género historiográfico, p. 84, así lo reconoce, aunque en el caso del Biclarense le resta importancia.

10 Dewing, H. B. (trad.). Buildings. Hutchinson, 1940, vol. 6. Véase también el prefacio de la Crónica del pseudo Dionisio de Tell-Mahré, escrita a finales del siglo viı (Снавот, J. B. (trad.). Chronique de Denys de Tell-Mahré: Quatrième partie. Paris, 1895).

11 Luc. Sam., Cómo debe escribirse la Historia, especialmente 29 (Zaragoza, J. (trad.). Obras. Madrid, 1990, vol. III).

12 Tinti, F. «Personal names in the composition and transmission of Bede's prose Vita S. Cuthberti». Anglo Saxon England, 2011, vol. 40, pp. 15-42.

13 GaLÁn, El género historiográfico, p. 81.

14 Ibidem, pp. 111-116.

15 Cardelle, Victoris Tunnunensis, p. 139*.

16 Mar. Aven., Chron., a. 569 (Mommsen, T. (ed.). MGH, AA, XI, Berlin, 1894). Greg. Tur., DLH, IV.3, 41 y V.15 (Krusch, B. y Levison, W. (eds.). MGH, SRM, I, Hannover, 1951). Aunque en la tradición manuscrita de los DLH también aparecen las variantes Albenus y Albaenus en relación con el título del capítulo VI.41. 
MIKEL POZO FLORES

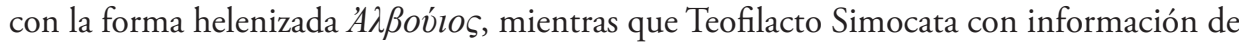
segunda mano usa A A $\lambda \beta o$ ĩ̈ añadiendo solo la marca del nominativo ${ }^{17}$. Juan de Biclaro se aleja de la forma germana y le da una apariencia clásica, por lo que bien pudiera ser un cultismo, no muy distinto por cierto, mutatis mutandis, del de Menandro. Lo mismo podría haber sucedido con el topónimo Ugerno, un oppidum situado en Beaucaire (Gard). Frente al Ugerno de los autores francos, el Hodierno del Biclarense exhibe una ortografía de aire mucho más clásico, con una $h$ inicial añadida que difícilmente se explicaría por la pronunciación de la época. En cuanto al nombre del rey merovingio Sigiberto, Cardelle entiende que la grafía correcta sería Sigisberti, pero ni siquiera en Gregorio de Tours hay una grafía única -es más, entre las variantes que usa no está precisamente esa ${ }^{18}-$. Y, por otro lado, la forma corriente en Hispania es la que usa Juan de Biclaro ${ }^{19}$.

No parece, pues, que los argumentos a favor de una Crónica basada esencialmente en fuentes orales sean sólidos. Sin embargo, esta opinión común ha tenido el efecto de orillar el problema que supone el tratamiento de otro tipo de fuentes. Cardelle ha admitido como única excepción el probable uso de las actas del III Concilio de Toledo ${ }^{20}$, lo que no deja de mostrar la diversidad de facetas del problema, si se piensa que M. C. Díaz y Díaz ha sugerido que, a la inversa, Juan de Biclaro pudo participar en la redacción de los discursos de Recaredo ${ }^{21}$. En cualquier caso, el amplio aparato de autores griegos que Campos recoge en su edición, como Juan de Éfeso, Evagrio Escolástico, Menandro Protector o Teófanes de Bizancio 22 , ha sido dejado al margen en el convencimiento de que son meros paralelismos explicables por la coincidencia de los acontecimientos a los que se refieren ${ }^{23}$. Creemos que el estado actual de la investigación obliga a preguntarse por la posible función de estas fuentes en la Crónica de Juan de Biclaro. Lo que está lejos de ser una cuestión sencilla: que se pueda razonablemente dudar de la primacía de las informaciones orales es una cosa y que se pueda identificar la presencia de otras fuentes, es otra muy distinta.

\section{USO Y DESCONTEXTUALIZACIÓN DE LAS FUENTES GRIEGAS}

J. N. Hillgarth fijó los términos básicos del problema de las fuentes griegas: hay sin duda pasajes de la Crónica que beben de autores bizantinos, pero es muy difícil identificar

17 Agradezco a Javier Alonso Aldama la ayuda prestada con las fuentes griegas. Men. Рrot., Hist., Frag. 12.1 (Blockley, R. C. (trad.). The History of Menander the Guardsman. Introductory Essay, Text, Translation and Historiographical Notes. Liverpool, 1985). Teоғ. Sim., Hist., vi.10.7 y 11 (Thesaurus Linguae Graecae).

18 Gregorio lo llama Sigiberto aunque con variantes en la grafía: Sygibertus, Sigibertus, Sigybertus, Sygiberthus, Sigiberthus, Sigyberthus, Syghibertus.

19 Sisibertus es el nombre del obispo al que se condenó en el XVI Concilio de Toledo por conspirar contra Egica: VIVEs, J. Concilios visigóticos e hispano-romanos. Barcelona-Madrid, 1963, pp. 507-509.

20 Cardelle, Victoris Tunnunensis, pp. 139*-140*.

21 Díaz y Díaz, M. C. «Los discursos del rey Recaredo: El Tomus». En Concilio III de Toledo. XIV Centenario 589-1989. Toledo, 1991, nn. 34 y 42.

22 Campos, Juan de Biclaro, p. 54.

23 Cardelle, Victoris Tunnunensis, p. 139*. 
MIKEL POZO FLORESA

LAS FUENTES EN JUAN DE BICLARO

su proveniencia exacta ${ }^{24}$. Juan de Biclaro no es el único autor de Occidente que opone esta dificultad a la investigación. Similares incertidumbres suscita Gregorio de Tours, cuyas informaciones y actitudes respecto al Imperio de Oriente -la hostilidad hacia Justino II o la alabanza de Tiberio II-, así como algún posible helenismo en su vocabulario, podrían provenir según A. Cameron de autores coetáneos, tales como Evagrio Escolástico o Juan de Éfeso ${ }^{25}$. Pero ni Cameron logra identificar la fuente exacta, ni su propuesta ha gozado del consenso de los especialistas ${ }^{26}$. Como telón de fondo, conviene además recordar que obras decisivas de la historiografía bizantina de este período se han perdido total o parcialmente, lo que incluso entre los autores griegos hace complicado seguir el hilo de las fuentes ${ }^{27}$.

Sin embargo, las fuentes griegas ofrecen suficientes puntos de referencia en su cronología y en su coherencia para permitir una aproximación algo diferente de la tradicional Quellengeschichte ${ }^{28}$. Comenzaremos por algunas observaciones secundarias y después examinaremos el pasaje relativo a los acontecimientos de Suania que nos parece particularmente esclarecedor.

No es difícil percibir en la Crónica de Juan de Biclaro el eco de la Historia Eclesiástica de Evagrio Escolástico, terminada hacia 593, sea directamente, sea porque hubiera fuentes comunes a ambos: las tres primeras entradas de Evagrio están entre las cinco primeras de Juan; la asunción del poder por Tiberio II se presenta en ambos casos con el mismo

24 Hillgarth, J. N. «Historiography in Visigothic Spain». En La storiografia altomedievale. XVII Settimana, 1969. Spoleto, 1970, p. 269, n. 228.

25 Cameron, A. "The Byzantine Sources of Gregory of Tours». The Journal of Theological Studies, 1975, vol. 26, n. ${ }^{\circ}$ 2, pp. 421-426.

26 McCormick, M. "Clovis at Tours, Byzantine Public Ritual and the Origins of Medieval Ruler Symbolism». En Chrysos, E. y Schwarcz, A. (eds.). Das Reich und die Barbaren. Wien, 1989, n. 33; Coumert, M. Origines des peuples. Les récits du Haut Moyen Âge occidental (550-850). Paris, 2007, p. 315, n. 391.

27 Wнiтву, M. The Emperor Maurice and his Historian. Theophylact Simocatta on Persian and Balkan Warfare. Oxford, 2002 [1988 ${ }^{1}$, pp. 107 y 243. El caso de Teofilacto Simocata es un ejemplo claro de ello: Whitby, M. y Whiтвy, M. (trads.). The History of Theophylact Simocatta. An English Translation with Introduction and Notes. Oxford, 1997 [1986¹], pp. xxi-xxv; Olajos, T. Les sources de Théophylacte Simocatta historien. Leiden, 1988.

28 Menandro Protector escribió en la segunda mitad del siglo vi una historia sobre las relaciones del Imperio con los territorios fronterizos (n. 17). Solo conocemos los fragmentos que se han conservado en la Suda. Juan de Éfeso compuso una Historia Eclesiástica en siriaco desde César hasta 588 de la cual solo se conserva completo el relato de los últimos años, entre 571 y 588 (Sмiтh, R. P. (trad.). The Third Part of the Ecclesiastical History of John Bishop of Ephesus. Now first Translated. Oxford, 1860). Juan de Epifanía redactó una historia de las relaciones entre Persia y el Imperio en las que había participado como legado y de la que solo se conservan algunos pasajes iniciales (MüLLER, K. (trad.). Fragmenta historicorum graecorum, 1981, vol. 4). Evagrio escribió su Historia Eclesiástica desde el I Concilio de Éfeso (431) hasta su propio tiempo (593) usando algunas obras anteriores, incluida la de su primo Juan de Epifanía (Whitby, M. (trad.). The Ecclesiastical History of Evagrius Scholasticus. Liverpool, 2000). Teofilacto Simocata compuso hacia 630 una historia en ocho libros sobre el gobierno del emperador Mauricio (582-602) a partir de fuentes escritas anteriores (n. 27). Teófanes el Confesor redactó a comienzos del siglo Ix una Crónica, que continuaba la de Jorge Sincelo, donde narra la historia del Imperio desde Diocleciano hasta 813 (Mango, C. y Scott, R. (trads.). The Chronicle of Theophanes Confessor. Byzantine and Near Eastern History AD 284-813. Oxford, 1997). 
recurso, enviando a una noticia anterior sobre su exitosa campańa contra los ávaros ${ }^{29}$. Al mismo tiempo, no cabe ninguna duda en cuanto a que Juan haya usado también fuentes independientes de las de Evagrio. El triunfo que sigue en Constantinopla a la victoria sobre Cosroes I figura en la obra de Evagrio ${ }^{30}$, pero el detalle exótico de los 24 elefantes, de los que también narra alguna anécdota Juan de Éfeso ${ }^{31}$, solo lo encontramos en el Biclarense $^{32}$. Del mismo modo, en el episodio de la conspiración de Eterio y Addaeo, tanto Evagrio como Juan hablan del intento de envenenamiento ${ }^{33}$, pero el primero nada dice de la complicidad de un médico. Puesto que un autor tardío como Teófanes el Confesor, que escribe a principios del siglo $\mathrm{IX}^{34}$, sí la recoge, cabe colegir que, o bien Juan utilizó una fuente común a Teófanes distinta de Evagrio, o bien que puso por escrito una información que circulaba por Constantinopla y que acabaría llegando de algún modo a la historiografía griega. La ejecución de Eterio y Addaeo estaba muy reciente cuando Juan llegó a la capital. Por su parte, Evagrio, que proporciona noticias mucho más detalladas sobre la personalidad y las declaraciones de los conspiradores, evoca una ejecución por decapitación mucho menos espectacular que las fieras y el fuego de Juan de Biclaro, lo que hace sospechar alguna licencia por parte de este último.

Estas primeras observaciones solo dejan entrever algún rasgo de la práctica de Juan de Biclaro. Este ha podido añadir detalles que sin duda impresionaron al joven que llegó a Constantinopla desde Lusitania -su gusto por las escenas exóticas ha sido señalado 35 y que han podido deformarse en su memoria. Podemos además sospechar que manejó textos perdidos. Hay en fin una cuestión de estilo impuesta por el estilo plano propio de la Crónica ${ }^{36}$ : el Biclarense es muchísimo más escueto que sus coetáneos griegos, lo que enmascara aún más una eventual dependencia de estos.

Algo más de luz arroja la relación entre el desastre de Dara (573) y la incapacidad de Justino II. La enfermedad del emperador fue considerada como el resultado del shock producido por la pérdida de Dara a manos de los persas, versión que recoge Evagrio ${ }^{37}$, o como una posesión demoníaca que castigó la persecución de los monofisitas, como dice una de las víctimas de la misma, Juan de Éfeso, que acabó su Historia Eclesiástica hacia $588^{38}$. Otros autores, como Juan de Epifanía, se limitan a hablar de enfermedad ${ }^{39}$. Por su parte, Juan de Biclaro se hace lacónico eco de ambas explicaciones y no se inclina por ninguna ${ }^{40}$. Ahora bien, lo que nos interesa es que el desastre militar y la incapacidad fueron dos acontecimientos de primer orden sucedidos cuando el Biclarense, subrayémoslo,

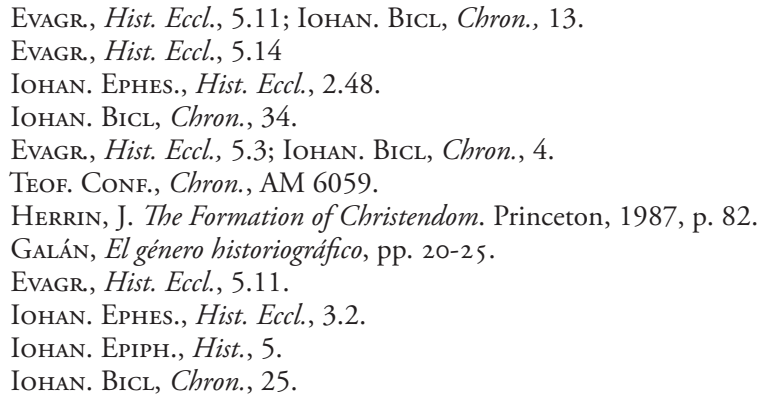


estaba estudiando en Constantinopla. Los autores griegos son concluyentes en cuanto al orden de los hechos: la derrota precedió a la locura ${ }^{41}$. Sin embargo, Juan invierte el orden y además los sitúa en años distintos, séptimo y octavo, del reinado de Justino II. ¿Por qué? Ciertamente no por la lógica de la parte de su relato que se refiere al Imperio. Ni establece relación entre un hecho y otro -a pesar de que alude a una agitación cerebral para explicar la enfermedad-, ni prosigue con la narración de la guerra, ni siquiera vuelve a refererirse a la locura del emperador en el nombramiento de Tiberio como César. Si hay una lógica en esta distorsión de la cronología, está en la construcción de una simetría con la parte hispánica de la Crónica. En efecto, la incapacidad de Justino aparece inmediatamente después de la ascensión de Leovigildo a la condición de soberano único del reino godo y el desastre de Dara produce un contraste no menos impactante con la victoriosa campańa de Cantabria que le sigue ${ }^{42}$. Subrayemos que el que Juan estuviera en Constantinopla aquellos años no parece ser óbice para que modele los hechos de Oriente en función del discurso sostenido por la Crónica.

Vayamos con el pasaje de Suania que anunciamos más arriba. En él, en el décimo año de Justino (575/576) -otra vez en tiempo de la estancia de Juan en Constantinopla-, aparece un personaje, el general Romanus, y las gentes de un territorio montañoso, Suania (Svaneti, Georgia), que no vuelven a ser mencionados en la Crónica de Juan de Biclaro:

Romanus filius Anagasti patricii magister milicie gentis Suanorum regem uirum cepit, quem cum suo thesauro, uxore et filiis Constantinopolim adducit et prouinciam eius in Romanorum dominio redigit ${ }^{43}$.

Otra vez, la función de este pasaje en la Crónica se aprecia en su paralelismo con la incursión de Leovigildo en los montes Aregenses y la captura de Aspidio y su familia que el Biclarense sitúa el año anterior ${ }^{44}$. Ambos responden al tema de la presentación del bárbaro vencido y encadenado ante el emperador ${ }^{45}$, tema que también utiliza el coetáneo Mario de Avenches al referirse a la victoria de Belisario sobre los vándalos ${ }^{46}$.

Ahora bien, ¿de dónde sale la noticia de la campaña de Romanus en Suania? Estos nombres solo aparecen una vez en la Crónica de Juan de Biclaro y de modo descontextualizado. No están conectados con ningún otro acontecimiento anterior o posterior. Si ocurriera lo mismo en las fuentes griegas, poco podría decirse a partir de eventuales discrepancias cronológicas. Pero no es así. Muy al contrario, la cuestión de Suania ${ }^{47}$, un territorio

41 Véanse notas 37-39.

42 Sobre los paralelismos, GALÁN, El género historiográfico, p. 125.

43 Iohan. Bicl, Chron., 38.

44 Leouegildus rex Aregenses montes ingreditur, Aspidium loci seniorem cum uxore et filiis captiuos ducit, opesque eius et loca in suam redigit potestatem (IoHAn. BICL, Chron., 35).

45 Teillet, S. Des Goths à la nation gothique. Les origines de l'idée de nation en Occident du ve au VII siècle. Paris, 1984, p. 417.

46 Mar. Aven., Chron., 534.2.

47 Bury, J. B. (dir.). The Cambridge Medieval History. Cambridge, 1911, vol. 2, pp. 266 y ss.; STEIN, E. Studien zur Geschichte der byzantinischen Reiches. Stuttgart, 1919, pp. 6, 20 y 69; RuBIn, B. Das Zeitalter Justinians. Berlin, 1960, vol. 1, pp. 526-530. 
MIKEL POZO FLORES

montañoso de valor estratégico habitado por gentes con fama de bandoleros, fue seguida con el mayor interés por los historiadores bizantinos. Menandro Protector dedica varias páginas a las negociaciones entre griegos y persas atascadas en la cuestión de Suania entre los reinados de Justiniano y Justino II ${ }^{48}$. Más tarde, la campańa de Romanus en Suania es narrada con detalle por Teofilacto Simocata ${ }^{49}$ que sigue seguramente las informaciones de primera mano de Juan de Epifaní ${ }^{50}$. El interés por la campaña se comprende si se tiene en cuenta que estas acciones militares griegas acaban desencadenando la deposición de Hormizd IV por el general Vahram y la proclamación de Cosroes II. La sucesión cronológica de los hechos es, pues, segura. Ocurre, sin embargo, que la campaña de Romanus tuvo lugar en 589, no antes. No, desde luego, en 575-576 durante la estancia de Juan de Biclaro en Constantinopla, sino el mismo año del III Concilio de Toledo. Además de la cronología, los detalles de la Crónica del Biclarense son harto dudosos: no hay desde luego un rey de Suania en la campaña de Romanus, un militar del que se empieza a tener noticias en acciones en Mesopotamia en los años $578-580^{51}$; el Anagastus que aparece como padre de Romanus sólo recuerda al personaje de nombre parecido que actúa en 469 como magister militum de Tracia ${ }^{52}$.

En nuestra opinión, estas constataciones no hacen sino corroborar la idea de que Juan de Biclaro es un historiador de su época, no exactamente un testigo. Eusebio de Cesarea declara no decir toda la verdad para centrarse en lo que beneficia a su Historia $^{53}$; a Jordanes le bastaron tres días sin tomar notas para releer la Historia de los Godos de Casiodoro ${ }^{54}$; las manipulaciones de Teofilacto Simocata han sido puestas de manifiesto por sus últimos estudiosos ${ }^{55}$. En lo que nos interesa aquí, el pasaje de Suania refuerza las observaciones anteriores y demuestra que el Biclarense utilizó fuentes griegas incluso en episodios que a primera vista podrían parecer transmitidos por su testimonio personal; pone en evidencia que el interés de la construcción de la Crónica estaba por encima de su propio recuerdo ${ }^{56} \mathrm{y}$ desvela que las fuentes escritas eran modeladas, resumidas y descontextualizadas ${ }^{57}$. Cosa que lógicamente dificulta su

48 Men. Рrot., Hist. Frag., 6.1-2 y 9.1-3.

49 Teof. Sim., Hist., iii.6.6 y ss. (Whitby y Whitby (trads.), The History, op. cit.).

50 Whitby y Whitby, The History, pp. xxi-xxii.

51 Teоғ. Sim., Hist., iii.6.17.

52 Demandt, A. Die Spätantike: römische Geschichte von Diocletian bis Justinian, 284-565 n. Chr. München, 2007 [1989'] , p. 221.

53 Hist. Eccl., VIII.i (citado en MacMullen, R. Christianity and Paganism in the Fourth to Eighth Centuries. New Haven, 1997, p. 17).

54 Jor., Get., praef(Mommsen, T. (ed.), $M G H, A A$, V.1. Berlin, 1882).

55 Whiтву y Whiтву, The History, pp. xxii.

56 Esto contradice la convicción en la «sinceridad» del Biclarense en aquellos hechos de los que habría sido testigo en su juventud en Constantinopla: GALÁN, El género historiográfico, p. 98.

57 Collins, R. «An historical commentary on Iohannis Biclarensis Chronicon». En Cardelle, Victoris Tunnunensis, pp. 110-148, ha señalado algunos ejemplos en los que las fechas del Biclarense y de otras fuentes no concuerdan. A modo de ejemplo, la guerra contra los gépidos y la muerte de Cunimundo se sitúan comúnmente en un contexto previo a la invasión longobarda de Italia (entre 560 y 567), no en 571 como lo hace Juan. O la elevación al trono longobardo de Autarico parece haber sucedido en 584 y no en 580 . Además, cabe seńalar que el Biclarense acorta en dos años la duración del gobierno de Justino II y lo compensa añadiéndoselos al de Tiberio II. 
MIKEL POZO FLORESA

LAS FUENTES EN JUAN DE BICLARO

identificación. Last but not least, el episodio de Suania sitúa unos años más acá de 589 la llegada de la información a Hispania ${ }^{58}$ y la composición de una parte relativamente temprana de la Crónica.

\section{El probable diálogo con las Historias de Gregorio de Tours}

Pensar en una posible influencia de los Diez Libros de las Historias de Gregorio de Tours tenía poco sentido de acuerdo con la visión tradicional de la Crónica del Biclarense que recordamos en el inicio del artículo. Sin embargo, una vez establecido que Juan de Biclaro, además de ser un intelectual de su tiempo con una formación de primer orden, compone una Crónica sustentada en el fondo y en la forma en un discurso político, no parece razonable excluir a priori esta hipótesis del análisis. Debe además pensarse que, con independencia de que nuestras propias conclusiones del apartado anterior sugieran una fecha de composición al menos bien avanzada en la década final del siglo vi, y de que las propuestas de redacción temprana dependan en buena medida de la consideración de Juan como narrador imparcial de testimonios propios o ajenos, en el estado actual de la cuestión la horquilla cronológica contemplada por los especialistas se extiende de 589 a 602. Recordemos que la fecha de publicación más temprana posible de las Historias de Gregorio de Tours es 594.

Una eventual relación de la Crónica con las Historias del Turonense se impone, pues, como una interrogante que se encadena con el estudio previo de la relación con los autores griegos. Desde el punto de vista formal y estilístico, la distancia con la historia de Gregorio de Tours es similar a la que separaba a Juan de Biclaro de Evagrio Escolástico o Menandro Protector. Viene impuesta por las reglas y la austeridad del estilo plano propio del género cronístico. Que en el Turonense las referencias a Hispania sean secundarias y dispersas - del reinado de Leovigildo se ocupa en una veintena escasa de pasajes de extensión muy desigual, repartidos entre los libros IV y VIII- no es óbice para lo que decimos, puesto que hemos visto que Juan no extrae los acontecimientos en función de su lugar en el relato de origen, sino en función del lugar y sentido que les va a dar en su Crónica.

Sin embargo, en lo que concierne al contenido, los términos deben invertirse con respecto a las noticias de origen oriental. Si Juan podía seleccionar y descontextualizar

58 El envío de cartas y obras, o los viajes para consultar trabajos de interés, eran práctica común, lo que permitía difundir obras relativamente recientes, aunque escritas en tierras lejanas. No es menos cierto que en Occidente se conservan muchas menos cartas que en Oriente, donde se ha comprobado que circularon en abundancia: Hunger, H. Die hochsprachliche profane Literatur der Byzantiner. München, 1978, vol. 2, pp. 199-239. En el reino visigodo se conserva el epistolario de Braulio de Zaragoza (Riesco, L. Epistolario de San Braulio. Introducción, edición critica y traducción. Sevilla, 1975). Sobre el envío de cartas en el reino merovingio: Wood, I. The Merovingian Kingdoms: 450-751. London-New York, 1994, pp. 24-27. Respecto a los viajes, cabe destacar el efectuado en 646 por el obispo Tajón de Zaragoza para copiar algunos trabajos de Gregorio Magno, según relata la Chron. Muz. 754, 23, 6-36 (López Pereira, J. E. (ed.). Crónica mozárabe de 754. León, 2009 [19801]). Asimismo, las cartas de Braulio de Zaragoza en las que le pide a Isidoro de Sevilla el envío de las Etimologías ponen en evidencia que las noticias de las obras circulaban antes incluso de que estas últimas estuvieran acabadas (Braul., Epist. 5). 
sin impedimentos las informaciones relativas al Imperio, cualquier eco de Gregorio de Tours en lo tocante a los asuntos de Hispania había de precisar de una inserción delicada en un relato y en el contexto político del que el autor participaba: baste recordar que Juan de Biclaro es por esos años el único autor de Occidente que niega la justificación religiosa a la revuelta de Hermenegildo, lo que no es poca cosa. Hay, en fin, una última diferencia sustancial: evidentemente, Juan de Biclaro no necesitaba a Gregorio de Tours para obtener información sobre el reinado de Leovigildo. Si lo utilizó, hay que pensar más bien en términos ora de diálogo, cuando Gregorio ofrece una visión aceptable, ora de alternativa, cuando Juan se ve obligado a sostener otra versión de los hechos.

Comenzaremos por una observación meramente formal, pero sugerente. Más allá de los problemas de sincronía que pueda tener, el sistema de doble datación que usa el Biclarense, por los reinados del emperador y los del rey godo, es perfectamente coherente con el espíritu de la Crónica, que sigue las evoluciones divergentes de Constantinopla y Toledo. Es también técnicamente brillante y muy original, en la medida en que no lo usan los historiadores occidentales u orientales de su época, ni tampoco los cronistas que le preceden -Víctor de Túnez- o que son sus contemporáneos, como Mario de Avenches ${ }^{59}$. Con una excepción: Gregorio de Tours utiliza esta rara práctica en cinco ocasiones en que data los acontecimientos en función de los años de reinado de dos o tres reyes francos (DLH, V.25 y 27; VI.14; X.10 y 24). En Gregorio de Tours es esporádico y en Juan de Biclaro es sistemático; en uno se explica por la arquitectura política merovingia y en otro por la introducción del regnum Gothorum en la Historia. Pero la coincidencia merece ser considerada, a título de indicio.

Si pasamos ahora al contenido, podemos comenzar por la parte en que Gregorio de Tours narra la ascensión de Leovigildo y su exitosa política de sumisión de los territorios de Hispania que escapaban al control visigodo:

De regibus Hispanorum.

Ergo, ut ad historiam recurramus, mortuo apud Hispaniam Athanaeldo rege, Leuva cum Leuvieldo fratre regnum accepit. Defuncto igitur Leuvane, Leuvieldus, frater eius, totum regnum occupavit. Qui, uxorem mortuam, Gunsuintham, reginae Brunichildis matrem, accepit, duos filios de prima uxore habens, quorum unus Sigyberthi, alius Chilperici filiam disponsavit. Ille quoque inter eos regnum aequaliter divisit, interficiens omnes illos qui regis interemere consueverant, non relinquens ex eis mingentem ad parietem ${ }^{60}$.

En Juan de Biclaro, estas informaciones básicas se siguen esencialmente en el mismo orden ${ }^{61}$, ampliadas claro está por las noticias de las campañas de Leovigildo que acaban con los que Juan califica de tiranos y usurpadores. El matrimonio de Leovigildo con Gosvinta y la mención del origen materno de Recaredo y Hermenegildo aparecen en ambos casos antes de la rebelión del segundo, a pesar de que su importancia no se percibirá hasta este suceso. Sobre un mismo fondo de acontecimientos, Gregorio

59 GALÁN, El género historiográfico, p. 89.

60 Greg. Tur., DLH, IV.48.

61 Iohan. Bicl., Chron., 6, 10, 24, 27 y 50. 
es más bien neutro y displicente con respecto a los triunfos de Leovigildo, mientras que Juan subraya la legitimidad de este frente a sus adversarios y tiñe sus victorias de un componente carismático ${ }^{62}$. Por otro lado, el Turonense prefiere referise a la hija de Gosvinta, que tendrá un papel importante en sus Historias, mientras que el Biclarense está lógicamente más interesado por su matrimonio anterior con Atanagildo ${ }^{63}$.

Poco puede deducirse de este paralelismo, en primer lugar porque son informaciones básicas y en segundo lugar porque, a falta de un tercer testimonio, mal puede valorarse si estos hechos que ambos comparten traducen una selección común que deja de lado otros acontecimientos de no menor rango. Sí puede, en cambio, apuntarse una observación que vuelve a tener en nuestra opinión valor de indicio. Mientras que Gregorio de Tours utiliza muy habitualmente Hispanus e Hispania para referirse al territorio y al reino -rex Hispanorum, rex Hispaniae, Hispanum limitem... ${ }^{64}$-, Juan de Biclaro se refiere más bien a los godos -rex Gothorum, Gothorum provincia, gens Gothica...-. Lo interesante es que de las seis veces que Juan de Biclaro utiliza Hispania en su Crónica, cuatro aparecen en los pasajes correspondientes al fragmento de Gregorio de Tours que hemos reproducido más arriba. La quinta mención está en relación al inicio de la rebelión de Hermenegildo -el episodio más detalladamente tratado por Gregorio- y la sexta tiene un valor distinto para distinguir en el III Concilio a los obispos de sedes peninsulares distintas de las del recién conquistado reino suevo. El que entre las cuatro primeras Juan inserte una rarísima Hispania citerior, que implicaría una inusitada Hispania ulterior para referirse a la Galia Narbonense, muestra lo consciente de la elección del término clásico. Es como si Juan de Biclaro estuviera pensando en un público externo al que dirige el mismo relato del Turonense, pero cargado con un discurso político distinto.

El segundo conjunto de episodios al que prestaremos atención es la piedra de toque para nuestra propuesta. Se trata de la rebelión de Hermenegildo. Naturalmente, es aquí donde Juan más se distancia de Gregorio. Califica de tiranía a la sedición, al igual que lo hará Isidoro de Sevilla, mientras que el Turonense conceptúa el enfrentamiento como persecución contra los católicos, visión que comparte Gregorio Magno ${ }^{65}$. Parece superfluo recordar que la naturaleza de la rebelión ha sido una de las cuestiones más debatidas por los historiadores ${ }^{66}$. Conviene, sin embargo, subrayar que el debate ha consistido generalmente en otorgar una mayor verosimilitud a un testimonio u otro. Nosotros nos

62 Iohan. Bicl., Chron., 10 y 50.

63 Iohan. Bicl., Chron., 10.

64 Greg. Tur., DLH, II.2, 9, 25, 26, 46; III.1, 2, 10, 29, 30, 37; IV.8, 26, 27, 38; V.33, 38, 40, 43; VI.18, 29, 33, 34, 40, 42, 43, 45; VII.10; VIII.28, 30, 35, 38, 43, 45, 46; IX.1, 6, 15, 22, 24, 28, 32; X.21, 23, 30.III.

65 Marcotegui, B. «El tratamiento historiográfico de San Hermenegildo». Anuario de Historia de la Iglesia, 2003, vol. 12, pp. 289-302.

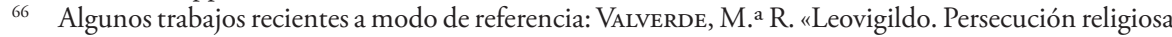
y defensa de la unidad del reino". Iberia: Revista de la Antigüedad, 1999, vol. 2, pp. 123-132; Marcotegui, "El tratamiento"; Vallejo, M. "Los exilios de católicos y arrianos bajo Leovigildo y Recaredo». Hispania Sacra, 2003, vol. 55, pp. 35-48; Toro, J. M. de. "Algunos aspectos políticos y religiosos de la rebelión de Hermenegildo». Intus-Legere, 2004, vol. 7, n. ${ }^{2}$ 2, pp. 51-56; BEsGA, A. «La rebelión de San Hermenegildo». Historia 16, 2007, vol. 377, pp. 24-49. 
preguntamos si algunos de los puntos más resbaladizos de la comparación entre ambas versiones no tienen más bien que ver con la construcción misma del texto, es decir, con el hecho de que el Biclarense pudiera haber introducido en su relato elementos extraídos de Gregorio de Tours para componer justamente la explicación alternativa.

Gregorio de Tours alude ampliamente a la guerra civil en V.38 y vuelve a mencionar el conflicto tangencialmente al relatar la llegada de ciertos embajadores procedentes de Hispania (VI.18, 33 y 40), la usurpación de Audeca acaecida tras la muerte del suevo Mirón (VI.43) y el supuesto intento de venganza de Guntram por el exilio y posterior muerte de su sobrina Ingunda (VIII.28). Los orígenes de estos dos últimos sucesos estarían en la rebelión de Hermenegildo. Pero, por lo general, Gregorio utiliza el conflicto, así como algún otro pasaje relacionado con el reino visigodo, para condenar la herejía arriana ${ }^{67}$.

Recordemos que, según Gregorio, los cristianos sufrieron persecución: muchos habrían sido exiliados, desposeídos, encerrados y torturados hasta la muerte. La causante de todos estos males habría sido la reina Gosvinta, cuyo ferviente arrianismo se pone de manifiesto en el modo brutal de tratar a su nieta Ingunda, princesa franca casada con Hermenegildo. Gosvinta le habría propinado una paliza y la habría obligado a convertirse al arrianismo sumergiéndola a la fuerza en la piscina bautismal. A pesar de ello, Ingunda nunca habría dejado de ser católica y, tan pronto como se instalaron en la residencia que Leovigildo había concedido a los recién casados, habría intentado persuadir a su marido para que se convirtiera a la fe verdadera. Finalmente, Hermenegildo habría visto la luz, siendo ungido y tomando el nombre de Juan. Inflamado por su anticatolicismo, Leovigildo habría empezado a cavilar sobre la forma de acabar con su hijo. Gregorio continúa narrando el intento hermenegildiano de establecer una alianza con los imperiales y el fracaso del mismo, una vez que Leovigildo había comprado la no intervención griega. Asimismo, involucra a Recaredo, quien, pese a prometer a su hermano el perdón paterno si aceptaba implorarlo, habría faltado a su palabra, de modo que Hermenegildo fue apresado primero, encarcelado en Toledo después y finalmente enviado al exilio con un solo esclavo. Gregorio concluye diciendo que Leovigildo habría ordenado dar muerte a su hijo.

Al discurso antiarriano, que tiene un cierto papel en la legitimidad del dominio franco sobre la Galia, Gregorio de Tours ańade aquí elementos de la propaganda que el bando hermenegildiano había difundido en la guerra civil: la conocida inscripción de Alcalá de Guadaír ${ }^{68}$ evoca el victimismo martirial que recogerán tanto el Turonense como Gregorio Magno ${ }^{69}$.

67 Moorhead, J. «Gregory of Tours on the Arian Kingdoms». Studi Medievali, 1995, vol. 36, pp. 903-915; Keedly, A. "Arians and Jews in the Histories of Gregory of Tours». Journal of Medieval History, 1997, vol. 23, n. ${ }^{\circ}$ 2, pp. 103-115. También aprovecha la llegada de un embajador visigodo para criticar el error arriano (Greg. Tur., $D L H$, V.43).

68 Ayala, C. de. Sacerdocio y reino en la España altomedieval. Iglesia y poder politico en el Occidente peninsular, siglos VII-XII. Madrid, 2008, p. 24.

69 Greg. Mag., Dialog., III.31. A pesar de tachar de hereje y parricida a Leovigildo, le atribuye el mérito de reconocer que la religión católica era la verdadera y de haberle pedido a Leandro que, al igual que había hecho con Hermenegildo, convirtiera también a Recaredo. Aunque en la narración del papa Leovigildo no se convierte por miedo a su pueblo, a diferencia de la versión de los $D L H$. 
Además del riesgo de legitimar la sublevación contra el rey, mal podía presentarse al linaje que ocupaba el trono de los godos como perseguidor de mártires, con el padre difunto como instigador y el hijo reinante como cómplice. El Biclarense opta, como se sabe, por cribar los acontecimientos: omite el dato fundamental de la conversión de Hermenegildo y la participación de Recaredo en el conflicto. Nada dice tampoco de los preparativos de la boda de este con Rigunta, hija del franco Chilperico, que por aquel entonces se estaban llevando a cabo, según Gregorio. A diferencia de este, nunca presenta a Hermenegildo tomando una iniciativa militar, sino que esta corresponde siempre a Leovigildo, como ocurre con respecto a los demás tiranos y usurpadores de Hispania. Por otro lado, la solicitud de auxilio a las tropas imperiales no solo presentaba como aliados al hermano de Recaredo y a la potencia que impedía el dominio godo de toda Hispania, sino que dejaba en una posición incómoda a Leandro de Sevilla ${ }^{70}$. De modo que nada de esto menciona el Biclarense.

Ahora bien, si a unos hay que protegerles del baldón de ser perseguidores del catolicismo y a otro hay que calificarle de tirano sin adjudicarle un motivo para el levantamiento -y sin acusarle de la insania asociada normalmente a la tiranía, puesto que es de la sangre de Recaredo-, el problema al que se enfrenta el Biclarense es en principio irresoluble: no hay manera de explicar la guerra civil. Mucho menos de presentar una versión alternativa a la que se difundía por los círculos de gobierno de Occidente. La solución de Juan de Biclaro consiste en aludir a una factio Gosvinthae reginae que ha hecho correr ríos de tinta y que enlaza en apariencia paradójicamente con una de las explicaciones de Gregorio de Tours.

Como se sabe, Juan de Biclaro y Gregorio de Tours hacen instigadora del conflicto a la reina Gosvinta. Se ha solido ver una contradicción entre una y otra versión ${ }^{71}$, de modo que la mayor parte de los historiadores se han decantado por dar una mayor verosimilitud a una u otra, o bien por renunciar a explicarlas. Así por ejemplo, E. A. Thompson sigue a Gregorio de Tours, J. Orlandis ve en la domestica rixa del Biclarense la alusión a la violencia de la abuela con su nieta de que habla el Turonense y L. A. García Moreno se limita a aludir al uso de la violencia por Gosvinta ${ }^{72}$. En 1994 Galán propuso seguir la lectura de Campos $^{73}$ y traducir factione Gosvinthae por «a causa de la actuación de Gosvinta» ${ }^{74}$, es decir, no como un ablativo de medio, sino de causa. Juan de Biclaro dejaría así entrever que el arrianismo de Gosvinta fue la causa de la rebelión. Más recientemente, $S$. Castellanos ha intentado establecer la coherencia de ambas versiones ${ }^{75}$. En su opinión, mueve a Gosvinta el deseo de hacer subir al trono a un miembro de su linaje, cual es su nieto Atanagildo, hijo de Hermenegildo e Ingunda. La conversión

70 La mención del Imperio podía haber implicado a Leandro de Sevilla, principal artífice de la conversión de los godos y alma del III Concilio de Toledo, tal como señaló Domínguez deL VAL, U. Leandro de Sevilla y la lucha contra el arrianismo. Madrid, 1981, p. 38.

71 Por ejemplo, BesGa, «La rebelión», p. 40.

72 Thompson, E. A. Los godos en España. Madrid, 1985 [The Goths in Spain. Oxford, 1969'1], pp. 8182; Orlandis, J. Historia del reino visigodo español. Madrid, 1988, p. 79; García Moreno, L. A. Historia de España visigoda. Madrid, 1989, p. 122.

73 Campos, Juan de Biclaro, pp. 131-132.

74 GaLÁn, El género historiográfico, p. 159.

75 Castellanos, S. Los godos y la cruz: Recaredo y la unidad de Spania. Madrid, 2007, pp. 113 y ss. 
arriana de Ingunda era pues indispensable en tanto que fe de los godos. En cuanto a la violencia de Gosvinta hacia su nieta, se debería al interés de Gregorio de Tours por vituperar a determinados personajes ${ }^{76}$.

Como todos los autores que se han ocupado de esto han puesto en evidencia, las incertidumbres siguen siendo más que considerables ¿Cómo puede la mujer arriana de Leovigildo provocar la revuelta católica de su yerno? ¿Cómo puede una disputa del entorno real degenerar en una guerra civil que subleva enseguida otros territorios además de Sevilla? ¿Por qué habría de ser el catolicismo de la mujer de Hermenegildo un problema para el heredero, siendo así que también Recaredo iba a casar con una princesa franca? Y todo esto, teniendo además en cuenta que Ingunda debía de tener unos doce ańos al llegar a Hispania. Como ha mostrado Keedly, Gregorio de Tours hace de Ingunda una mártir en vida ${ }^{77}$. Según el modelo de Clotilde y Clodoveo, es el instrumento para incorporar a su marido a la Iglesia verdadera. Ingunda vence a la pérfida arriana, a quien Dios castiga con el mal de cataratas.

No pretendemos que las disquisiciones sobre el papel de los bandos familiares en el desencadenamiento de la guerra sean vanos ni mucho menos. Pensemos por ejemplo en la conexión de sectores importantes de la aristocracia hispalense con Gosvinta que, tal como sostiene Castellanos ${ }^{78}$, es sin duda un factor de importancia decisiva en la rebelión. Pero creemos que deben distinguirse dos planos de análisis: la lógica política de las actitudes de los protagonistas y de los acontecimientos es una cosa, y la lógica de construcción del texto es otra. No porque esta sea independiente de los primeros, sino porque juega con un cierto grado de autonomía y con la necesidad de asegurar una coherencia interna. El problema de los intentos de explicación, en relación al Biclarense, es que pretenden dar una coherencia basada en el desarrollo de los acontecimientos a lo que, creemos, se construyó en función de otras coordenadas.

Examinemos el factione Gosuinthae en la práctica de Juan de Biclaro. En su Crónica se mencionan mujeres doce veces, de las cuales ocho se refieren a ellas de forma pasiva, cuando no anónima: son las esposas de miembros de las familias reinantes en el Imperio, en Toledo o en el reino suevo, o bien las de rebeldes hechos prisioneros, como el Aspidio de los montes Aregenses que evocamos más arriba. De modo activo, solo figuran tres mujeres en la Crónica: la esposa de Justino II, Sofía Augusta, la del rey lombardo Alboino, Rosamunda - de la que Juan no da el nombre-, y, naturalmente, Gosvinta. Las tres aparecen implicadas en graves y oscuros sucesos ocurridos en la cúspide de sus respectivos reinos y en los tres casos acaba muriendo algún hombre de sangre real. Con las tres, y solo con ellas tres, utiliza el Biclarense la misma expresión: factione Sophie Auguste, factione coniugis sue, factione Gosuinthae ${ }^{79}$.

En relación al juego de insidias, destierro camuflado y asesinato con que Justino II se deshizo del general Justino como potencial contendiente por el trono, el Biclarense se limita a recoger escuetamente la muerte de este último en Egipto y sugerir la instigación

76 Ibidem, p. 114.

77 Keedly, «Arians and Jews», p. 106.

78 Castellanos, Recaredo, p. 115.

79 Iohan. Bicl., Chron., 5, 23 y 54. 
de la emperadora Sofía con la expresión citada. Juan de Biclaro es el único cronista que, de modo vago y hermético, eso sí, apunta en este sentido, si bien la participación activa de Sofía en la política de su marido desde aun antes de la accesión al trono era conocida y difundida por los autores coetáneos ${ }^{80}$.

Más ilustrativo nos parece el tratamiento de la mujer de Alboino, de la que como hemos dicho ni siquiera da el nombre. A diferencia de la eventual responsabilidad de Justino II y Sofía en el asesinato de Justino, el papel de Rosamunda en la muerte del rey lombardo no podía generar ningún contratiempo personal a historiadores y cronistas. De este modo, Teofilacto Simocata pone en boca de un prisionero bárbaro un novelesco relato según el cual Alboino se había enamorado de Rosamunda, hija del rey de los gépidos Cunimundo, y la había raptado, dando con ello inicio a la guerra en la que mataría al padre de su amada ${ }^{81}$. Gregorio de Tours narra la conspiración de Rosamunda contra el asesino de su padre y la complicidad de un servidor que envenena a Alboino y huye con ella. Al final, ambos son capturados y muertos ${ }^{82}$. Paulo Diácono narraría mucho después un truculento episodio de crueldad de Alboino hacia Rosamunda, obligada a beber en el cráneo de su padre ${ }^{83}$. Juan de Biclaro le da al episodio un tratamiento similar al de Mario de Avenches, que deja ver la instigación bizantina del complot. Pero el Biclarense, y esto es lo que nos interesa, difumina los sucesos hasta tal punto que parece que tras el fracaso de la conspiración la reina hubiera huido sola con el tesoro del reino a refugiarse entre los bizantinos. Todo queda sugerido pero inexplicado tras el consabido factione coniugis suae $^{84}$. La comparación de los dos tratamientos nos parece interesante, porque en este caso ambos se enfrentan a los mismos condicionantes de estilo del género cronístico:

Hoc anno Albuenus rex Langobardorum a suis, id est, Hilmaegis cum reliquis consentiente uxore sua Verona interfectus est: et supra scriptus Hilmegis cum antedicta uxore ipsius, quam sibi in matrimonium sociaverat, et omnem thesaurum, tam quod de Pannonia exhibuerat quam quod de Italia congregaverat, cum partem exercitus, Ravennae rei publicae se tradidit ${ }^{85}$.

Aluinus Longobardorum rex factione coniugis sue a suis nocte interficitur, thesauri uero eius cum ipsa regina in rei puplice Romane ditionem obueniunt, et Longobardi sine rege et thesauro remansere ${ }^{86}$.

En Juan de Biclaro, el factione dependiendo de una mujer basta para aludir a su responsabilidad y exime de mayores explicaciones. Estaríamos tentados de decir que estos antecedentes nos dan claves sobre el pasaje referido al origen de la rebelión de Hermenegildo. Pero debemos tener presente que nada indica que el Biclarense decidiera la redacción de cada pasaje, y aun la elección de los acontecimientos a registrar, en orden

80 Evans, J. A. S. The Age of Justinian. The Circunstances of Imperial Power. London, 2000 [1996'] , p. 265.

81 Teof. Sim., Hist., vi. 7-11.

82 Geg. Tur., DLH, 4. 41.

83 Paul. Diac., Hist. Lang., 2.28 (Bethmann, L. y Waitz, G. (eds.). MGH, SS rer. Lang. Hannover, 1878).

84 En la Crónica ha registrado antes la muerte de Cunimundo (IoHan. Bicl., Chron., 19), sin relacionarla con el episodio posterior de Alboino y su mujer.

85 Mar. Aven., Chron., a. 572.

86 Iohan. Bicl., Chron., 23. 
MIKEL POZO FLORES

cronológico. Ya hemos visto cómo juega con el orden temporal de algunos hechos, si es menester. Es decir, que ignoramos si aplica a Gosvinta el tratamiento que antes ha concretado con Sofía y Rosamunda, o bien si introduce en otras partes de la Crónica la fórmula que le va a permitir salvar la severísima dificultad que expusimos arriba. De este modo - pero no lo sabemos- podía enmarcar la solución a su dilema en paralelos correspondientes a otros ámbitos políticos.

Con independencia de los hechos, de las motivaciones de Hermenegildo, de la amplitud de los apoyos que recibiera de la aristocracia católica, de la colaboración de dirigentes de la Iglesia y, si se quiere, de la actitud de Gosvinta, y sabiendo que con los condicionantes con que trabaja el Biclarense la explicación es imposible, Gosvinta es la responsable perfecta. Catholicis semper infesta, no solo es una ferviente arriana ajena a la sangre de Leovigildo que osa aún conspirar contra Recaredo tras la conversión de este ${ }^{87}$, sino que ha sido también señalada como culpable por Gregorio de Tours, campeón del catolicismo. Es la única culpable a la que el Biclarense no tiene que defender u ocultar. En nuestra opinión, la dificultad de la coincidencia en el papel de Gosvinta en ambas obras se resuelve si se contempla la posibilidad de que el Biclarense la tome del Turonense como estrategia para callar en el interior del reino ciertas implicaciones en la revuelta -implicaciones que todos conocían por otro lado- y para hacer pivotar su voluntariamente difusa explicación sobre un punto de acuerdo con Gregorio de Tours, de cara al exterior. Es decir, que no derivaría de una paradójica, cuando no enigmática, lectura común de los hechos, o de una casualidad extraordinaria, sino de la lógica interna de la Crónica.

Junto a este aspecto central, hay acontecimientos derivados de la resolución de la guerra civil en los que llama la atención la utilización de elementos presentes en las Historias de Gregorio de Tours. Ninguno de ellos es concluyente, pero, una vez más, cabe hablar de indicios concordantes en la forma y el contenido. Así, por ejemplo, Juan de Biclaro no dice naturalmente que el asesino de Hermenegildo fuera Leovigildo, como hace Gregorio de Tours ${ }^{88}$, sino que acusa a un tal Sisberto que sería víctima de una muerte vergonzosa bajo el reinado de Recaredo ${ }^{89}$. Es llamativo que Sigiberto I, padre de Ingunda y yerno de Gosvinta, tuviera una muerte indigna -en Victoriaco, dicho sea de paso-. Según Gregorio de Tours, dos sicarios le clavaron en los costados sendos scramasax envenenados y falleció entre alaridos. Claro que el rey Sigiberto no mató a Hermenegildo, pero nos preguntamos si el Biclarense no se inspiró en esta escena para dar un nombre -de un franco emparentado con Gosvinta, por cierto- a un oscuro sicario.

En este mismo sentido, en la narración de los hechos que siguen en el reino suevo a la intervención de Mirón en la contienda, hallamos en el Biclarense algunos paralelismos formales con el pasaje VI.43 de Gregorio de Tours que conviene apuntar ${ }^{90}$ : frente a

87 Gregorio dice que Recaredo llegó a un acuerdo con Gosvinta y la aceptó como si fuera su propia madre (DLH, IX.1).

${ }_{88}$ Leuvichildus vero Herminichildum filium suum, quem antedicta mulier habuit, morti tradedit (GREG. Tur., DLH, VIII.28)

89 Sisbertus interfector Hermenegildi morte turpissima perimitur (IoHAn. Bicl., Chron., 83).

90 Aunque Gregorio hace de Mirón un aliado del rebelde y Juan de Leovigildo: IsLA, A. «Las relaciones entre el reino visigodo y los reyes merovingios a finales del siglo vI». En la España Medieval, 1990, vol. 13, pp. 26-27, n. 55. 
MIKEL POZO FLORESA

LAS FUENTES EN JUAN DE BICLARO

Herminichildus [...] in civitate quadam Hispaniae cum coniuge resediret, de imperatoris solatio fretus atque Mironis Galliciensis regis, en Gregorio de Tours, encontramos en el Biclarense ciuitatem Ispalensem congregato exercitu obsidet et rebellem filium graui obsidione concludit, in cuius solatio Miro Sueuorum rex ad expugnandum Ispalim aduenit. Frente a Audica [...] adpraehensumque clericum facit ac diaconatus sibi praesbiterii ei inponi honorem iobet, en Gregorio de Tours, escribe Juan de Biclaro Audeca uero regno priuatus et honore presbyterii post regnum honoratur. Esto no es óbice para que se den también notables diferencias de contenido. Gregorio de Tours también tenía sus problemas, y no era el menor el de explicar por qué pierde la guerra el defensor de la fe verdadera. La decisión de Hermenegildo de salir a enfrentarse con su padre al frente de sus trescientos mejores hombres ${ }^{91}$ sirve a Gregorio de Tours para mostrar que el haberse alzado contra su padre ${ }^{92}$ le lleva a la perdición. El Biclarense en cambio no necesita esto -y tampoco le bastaría, pues ha de condenar la rebelión en sí misma-y prefiere presentar a un Leovigildo siempre dueño de la iniciativa contra la tiranía.

A la luz de todo lo anterior, cobra un valor destacable el hecho de que, en una perspectiva de conjunto, los sucesos políticos relativos al reinado de Leovigildo presentan una selección y un orden análogos en Gregorio de Tours y en Juan de Biclaro. Y esto más allá de lo que cabe esperar por la mera sucesión temporal y la importancia de los acontecimientos.

Observemos los ańos decisivos que siguen al estallido de la rebelión de Hermenegildo. Ambos autores coinciden en señalar los siguientes acontecimientos: cambio doctrinal en el arrianismo (57); campańa en Vasconia (60); breve alusión al conflicto de Hermenegildo (64); ataque de Leovigildo contra el rebelde y hechos relativos al reino suevo (65-67); captura y posterior exilio de Hermenegildo (68); ocupación franca de la Narbonense y victoria de Recaredo; muerte de Leovigildo y entronización de Recaredo $(79)^{93}$. Más allá de que Juan de Biclaro ponga en el orden cronológico correcto el destronamiento de Audeca, puede muy bien apreciarse que ni la selección de los hechos ni su orden de presentación van de suyo.

Puede pensarse en una casualidad, pero dudamos de que a estas alturas del análisis tal sea la hipótesis más económica. En cualquier caso, puede ser ilustrativa la introducción de un tercer elemento en la comparación. Mario de Avenches es contemporáneo de Juan de Biclaro y de Gregorio de Tours, si bien murió en 596, poco después, por tanto, que el Turonense y bastante más joven que el Biclarense. Escribe su Crónica en el reino merovingio de Borgońa y naturalmente coincide en diversos episodios con pasajes de las Historias de Gregorio de Tours. En este caso no hay duda de que no pudo utilizar esta obra $^{94}$, así que se encuentra en la misma situación con respecto al Turonense que la que se le ha venido suponiendo a Juan de Biclaro: escribe desde el ámbito político donde

91 Greg. Tur., DLH, VI.43.

92 Gregorio asimila la victoria de Leovigildo contra su hijo rebelde, al igual que la de Clotario sobre su hijo Chramo, a la de David sobre Absalón: Teillet, Des Goths, p. 380.

93 Las correspondencias son 57: V.38, 43, VI.18, 40; 60: VI.12; 65-67: VI.43; 68: V.38, VI.40, 43; 73: VIII.28; 74: VIII.30; 75: VI.43; 79: VIII.46, IX.1.

94 Favrod, A. «Les sources et la chronologie de Marius d'Avenches». Francia, 1981, vol. 9, pp. 1-21. 
transcurren la mayoría de los acontecimientos independientemente de Gregorio. Sin embargo, si tomamos los registros referidos al entorno del rey Guntram de Borgońa entre 576 y el fin de la Crónica de Mario en 581 -un tramo similar al que hemos tomado para el Biclarense- observamos una divergencia mucho más marcada que la que vemos entre el Biclarense y Gregorio de Tours con respecto a Leovigildo. Mario de Avenches da detalles que ignora Gregorio, como los nombres de los médicos que pagan con su vida la muerte de la segunda esposa de Guntram ${ }^{95}$, pero nada dice de hechos decisivos en la historia política del reino que sí se encuentran en el Turonense: ni la adopción de su sobrino por Guntram para hacerle heredero del reino, ni la guerra dirigida en nombre del rey por el patricio Mummolus, ni la ruptura de la paz con Childeberto, amén de episodios, si se quiere menores, como el asesinato de dos ex cuñados o la detención de los embajadores suevos ${ }^{96}$. Juan de Biclaro, en cambio, no deja en el tintero ningún acontecimiento importante narrado por Gregorio de Tours en relación al reinado de Leovigildo.

Los pasajes 57 y 60 del Biclarense merecen ser analizados con algo más de detenimiento, porque existe una aparente inversión en el orden y porque a primera vista podría parecer que los temas de Juan y Gregorio no están relacionados. Los testimonios del obispo turonense dejan ver que durante este tiempo se estaba produciendo un cambio en la doctrina arriana. En V.43 menciona la conversación sobre asuntos religiosos que Gregorio mantuvo con el embajador Agila, cuyo discurso refleja los principios tradicionales del arrianismo visigodo ${ }^{97}$. Igualmente, en V.38, a propósito de la conversión forzada de Ingunda, se refiere a la exigencia de ser rebautizado para convertirse al arrianismo. En cambio, en VI.18 se desprende una variación doctrinal de las palabras que pone en boca del embajador franco Argimundo a su regreso de Hispania. Lo mismo se deduce en VI.40 de la actuación del visigodo Opila durante una misa en Tours. Juan de Biclaro recoge en 57 todo este cambio aludiendo al concilio arriano convocado por Leovigildo en Toledo y del que ninguna otra fuente se hace eco ${ }^{98}$. En él se facilitaba la conversión de los católicos al arrianismo y se minimizaba la diferencia dogmática por medio de la aproximación al Macedonianismo99. También se suprimía la necesidad de ser nuevamente bautizado a la que alude Gregorio en el violento episodio de Gosvinta con su nieta. Creemos que Juan de Biclaro tiene en mente V.43 para introducir su pasaje y sintetiza las informaciones que en Gregorio están dispersas en cuatro capítulos.

Entre los pasajes V.43 y VI.18, Gregorio recoge al final de VI.12 la expedición del duque franco Bladastes a Vasconia ${ }^{100}$. A continuación del concilio arriano, también Juan de Biclaro se refiere a una campańa en esa misma región, si bien llevada a cabo por Leovigildo ${ }^{101}$. Allí donde Gregorio envía a Bladastes, Juan manda a Leovigildo, y allí donde

Mar. Aven., Chron., a. 581.1.

9 Greg. Tur., DLH, V.13, 17, 41; VI.1.

97 Orlandis, J. «El arrianismo visigodo tardío». Cuadernos de Historia de España, 1981, vol. 66, p. 12.

98 No deja de sorprender que sea la única noticia de un concilio arriano desde Arrio hasta la conversión de godos y lombardos del que tenemos constancia tras el cierre de la controversia en el siglo rv.

99 OrLandis, «El arrianismo», pp. 5-20.

100 Bladastis vero dux in Vasconiam abiit maximamquae partem exercitus sui amisit (GREG. TUR., DLH, VI.12).

101 Leonegildus rex partem Vasconiae occupat et civitatem quae Victoriaco nuncupatur condidit (IoHAN. BicL., Chron., 60). 
el general merovingio pierde la mayor parte de su ejército, el rey godo consigue una nueva victoria. Existe una distorsión aparente respecto al orden de Gregorio de Tours, pues este se refiere primero a la acción de Vasconia (VI.12) y después a la conversación con el emisario de Chilperico en la que se aprecia la modificación de la doctrina arriana (VI.18). Pero la lectura de VI.18 aclara la confusión, en la medida en que permite distinguir entre el momento en que se produce el diálogo y el momento en que ocurren los hechos narrados por el embajador. Los cambios doctrinales que menciona Gregorio, puestos en boca del emisario, debían haberse producido varios meses antes de su conversación. Por lo tanto, Juan de Biclaro no hizo sino organizar los pasajes en el orden correcto.

En fin, el Biclarense no tiene en cuenta los capítulos en los que Gregorio alude a diversas embajadas y algún otro en el que informa sobre una plaga de langosta ${ }^{102}$. Por lo general, son menciones lacónicas de idas o venidas de emisarios de Leovigildo o Chilperico ${ }^{103}$. Juan de Biclaro no muestra mayor interés en las relaciones de los godos con los francos, y a diferencia de Mario de Avenches o Hidacio, por ejemplo, no presta atención a los desastres naturales. Otra cosa son los pasajes en los que la llegada de embajadores da pie para criticar el arrianismo y referirse a la guerra contra Hermenegildo, que sí interesa a Juan de Biclaro. En sentido contrario, Gregorio de Tours no reseña detalles como la restauración de los muros de Itálica o la usurpación de Malarico en los estertores del reino suevo.

No pretendemos ni mucho menos que la Crónica se explique en función de las Historias de Gregorio de Tours. Pero sí nos parece que, en lo que se refiere al reino de los godos, la comparación de su estructura general y de ciertas explicaciones fundamentales con la obra del Turonense apunta a su conocimiento y utilización por parte de Juan de Biclaro. Y lo que es más importante, contemplado este diálogo entre ambas obras, la del Biclarense gana en inteligibilidad.

\section{Construcción de la CRÓNICA y CONTEXTO POlítico e INTElectual}

Como señalamos más arriba, en el estado actual de la cuestión es perfectamente defendible que Juan de Biclaro tuviera tiempo para utilizar tanto las Historias de Gregorio de Tours como textos historiográficos griegos posteriores a su estancia en Constantinopla. Naturalmente, nuestro examen de las fuentes apunta a la parte más baja de la horquilla cronológica, pero evitaremos caer en un razonamiento circular. Los argumentos que en nuestra opinión refuerzan la idea de una composición relativamente tardía de la Crónica son independientes de las fuentes, aunque coherentes con estas.

La tesis tradicional sostiene que Juan escribió su Crónica entre finales de 589 y $591^{104}$, antes de su acceso a la cátedra episcopal de Gerona. Esta tesis depende tanto de la consideración de Juan como un testigo cuya obra es esencialmente un relato sincero, como de una serie de

102 Greg. Tur., DLH, V.41; VI.29, 34 y 45; VII.10; VIII.35, 38 y 45.

103 Las excepciones son V.41 que se refiere a la captura de una embajada sueva que pasaba por los territorios de Chilperico y VII.10 en el que no es Chilperico, sino Guntram quien envía una embajada al reino visigodo.

104 Campos, Juan de Biclaro, p. 54. 
indicios poco concluyentes. En apoyo de esta cronología se ha alegado la segunda prescripción hecha por un monje en uno de los manuscritos, según la cual la historia era obra de Juan, abad fundador del monasterio. Esto significaría que el escrito se publicó teniendo Juan solo la dignidad de abad, porque de lo contrario se hubiera utilizado el título superior de obispo ${ }^{105}$. A partir de aquí, los pasajes 63 y 81, que recogen la duración del reinado del emperador Mauricio y del papado de Gregorio Magno, y que nos llevan hasta 602, se consideran inevitablemente interpolaciones. Mommsen creía que fue el Biclarense quien añadió estas nota ${ }^{106}$, mientras que Campos supuso que eran añadidos posteriores, porque sobrepasan el límite cronológico con el que se cierra el relato y porque, pese a seguir viviendo durante esos años, Juan tan solo refirió los hechos anteriores al año IV de Recaredo y VIII de Mauricio ${ }^{107}$. Subyace a esto la convicción de que una crónica se escribe poco después de los últimos hechos que relata.

Por su parte, Díaz y Díaz pensaba que el monje de Biclaro autor de una segunda introducción también completó estos datos. De aquí partiría toda la tradición textual ${ }^{108}$. Más recientemente, Cardelle ha considerado que estos testimonios serían del propio Juan de Biclaro, quien habría escrito su Crónica en $602^{109}$. Aunque cree que lo esperable hubiese sido terminar la obra en el año en que se escribe, el desenlace positivo de los dos temas centrales tratados en la misma justifican su final en 589: la victoria de la ortodoxia frente a la herejía y del poder central contra los intentos de rebelión ${ }^{110}$.

Sin embargo, no se ve por qué el escriba del monasterio de Biclaro tendría que referirse necesariamente a Juan como obispo, siendo así que la obra que tenía entre manos era la de su abad fundador. En el mismo sentido, el que la recensión de 602 de la que parte toda la tradición textual fuera obra de un monje depende de la convicción de que Juan acabó la obra en 590. Tampoco es evidente que 602 tenga que ser necesariamente el año de su redacción. Si realmente esas referencias a la duración del reinado fueron hechas por el propio Juan, solo estarían indicando una fecha post quem. Juan de Biclaro pudo perfectamente publicar su Crónica en cualquier momento entre 602 y la fecha en la que Isidoro de Sevilla la consultó para escribir la primera redacción de su crónica universal, en torno a 615/616. Tampoco puede descartarse la posibilidad de que el Biclarense pudiera haber trabajado en su elaboración a lo largo de varios ańos o en diversas etapas y que pudiera haberla modificado en más de una ocasión.

En realidad, que la Crónica fuera escrita al poco del III Concilio de Toledo suscita más problemas que los que resuelve. La profunda originalidad de Juan de Biclaro como enlace entre la historiografía imperial y la hispanogoda ha sido perfectamente explicada. El Biclarense inserta en la Historia el joven reino visigodo católico ${ }^{111}$. Si Eusebio de

105 Ibidem.

106 Mommsen, $M G H, A A$, XI, p. 208.

107 Campos, Juan de Biclaro, p. 53.

108 DíAz y DíAz, M. C. «La transmisión textual del Biclarense». En De Isidoro al siglo XI. Ocho estudios sobre la vida lieraria peninsular. Barcelona, 1976, [Analecta Sacra Tarraconensia, 1963리 , vol. 35, pp. 57-76], pp. 127-129.

109 Cardelle, Victoris Tunnunensis, p. 130*

110 Ibidem, p. 135*.

111 HillgarTh, «Historiography», pp. 263-265 y 268-269; GaLÁN, El género historiográfico; Álvarez García, F. «Tiempo, religión y política en el «Chronicon» de Ioannis Biclarensis». En la España Medieval, 1997, vol. 20, pp. 14 y ss. 
Cesarea concebía la universalidad cristiana bajo un emperador cristiano, en la Crónica del Biclarense se produce el cambio hacia esa misma universalidad cristiana articulada ahora con los diferentes reinos post-romanos ${ }^{112}$. Siguiendo la idea directriz de Leandro en la homilía del III Concilio de Toledo, según la cual los príncipes y reyes bárbaros sienten la necesidad de acercarse a la Iglesia para entrar en la Historia, Juan narra la adopción de la fe católica por otros pueblos -armenios, íberos, garamantes, macuritas e incluso el emperador de los persas-. En este contexto debemos situar también la noticia de la restauración de la ortodoxia por Justino II y, claro está, la conversión del regnum Gothorum, que constituye el acontecimiento más trascendental de la Crónica. Juan de Biclaro introduce y singulariza al pueblo godo en la Historia cristiana gracias a su conversión ${ }^{113}$. El III Concilio de Toledo sirve como acta de nacimiento del nuevo reino visigodo católico que goza del favor divino ${ }^{114}$.

En nuestra opinión, se aprecia aquí otro de los desajustes entre los avances de la investigación y la inercia de ciertas convicciones antiguas. En efecto, la originalidad de la concepción de la Crónica se traduce no solo en su tratamiento de la historia reciente del pueblo godo, sino, quizá sobre todo, en su construcción. Galán ha puesto el foco sobre la espectacular desproporción entre las diversas partes de la Crónica: nada menos que el $27 \%$ del texto corresponde a las últimas cinco noticias, mientras que el resto se lo deben repartir las 89 restantes. Solo el III Concilio ocupa el $14 \%$ del texto ${ }^{115}$. Basta una mirada rápida a la distribución del contenido en, por ejemplo, Próspero de Aquitania, Víctor de Túnez o Mario de Avenches para ver que semejante desigualdad separa radicalmente a Juan de Biclaro de los demás cronistas tardorromanos. Es más, todo el contenido del texto está perfectamente medido y articulado para gravitar en torno al gran acontecimiento final. Tan es así, que Galán aprecia que la Crónica está reordenada en torno a la conversión del reino ${ }^{116}$ y Teillet ve un abandono del género cronístico en la última parte para pasar a formas literarias ${ }^{117}$. Que el conjunto esté perfectamente trabado implica una reconstrucción cuidadosa y aun sofisticada de las décadas anteriores a 589. ¿Cómo pensar entonces en un proceso de composición de la obra cercano, cuando no simultáneo, al último año registrado, similar al de otros cronistas como Víctor de Túnez, cuando en estos en ninguna manera se da semejante reconstrucción orientada del mismo? Es más, ¿no deberíamos incluso contemplar la posibilidad de que la Crónica se redactara en el contexto de la construcción del discurso de legitimación de la nación goda ${ }^{118}$, es decir, más cerca de los trabajos de Isidoro de Sevilla que de las campańas de Leovigildo?

112 Áluvarez García, «Tiempo, religión y política», p. 15.

113 Ibidem, p. 19.

114 El catolicismo niceno se convierte en el principal factor de identidad del reino y también de fortalecimiento del poder regio: NAVARRO, C. «El giro recarediano y sus implicaciones políticas: el catolicismo como signo de identidad del Reino visigodo de Toledo». Revista de Ciencias de las Religiones, 2000, vol. 5, pp. 97-118.

115 Galán, El género historiográfico, p. 106.

116 Ibidem.

117 Teillet, Des Goths, pp. 428 y ss.

118 Véase por ejemplo Ibídem, pp. 463-536. 
MIKEL POZO FLORES

Cardelle cree que en 602 existían buenos motivos para escribir la Crónica, puesto que tras la muerte de Recaredo ascendió al trono su hijo Liuva II, de tan solo dieciocho años, sin el consenso de los magnates del reino ${ }^{119}$. Era una circunstancia propicia para que se produjeran rebeliones, tal y como sucedió poco después, y convenía justificar la posición del nuevo monarca. La argumentación de Cardelle es razonable, pero períodos en los que el riesgo de una rebelión era grande no faltan. Varios motivos, distintos pero coherentes, debieran hacer considerar la posibilidad de que Juan de Biclaro publicase su Crónica en el reinado de Sisebuto. Al igual que bajo el gobierno de Liuva II, también durante el mandato de Sisebuto surgieron conflictos entre facciones de la aristocracia. No en vano el propio monarca murió envenenado según la versión breve de la Historia Gothorum ${ }^{120}$. Pero Sisebuto, a diferencia de Liuva II, era hombre experimentado en asuntos de gobierno y contaba además con el apoyo de destacadas personalidades intelectuales, como Isidoro de Sevilla. Tenía iniciativa en materia literaria, como es bien conocido, y probablemente alentó a Isidoro a que elaborase sus dos obras historiográficas, la Crónica y la Historia Gothorum ${ }^{121}$. Como Isidoro, también Juan pudo trabajar en estrecha vinculación con el entorno regio ${ }^{122}$. Dos argumentos sostienen esta propuesta. Por un lado, la concepción general de la obra, que explica el nacimiento del reino godo católico y su creciente poder frente al Imperio, al que se estaba por fin derrotando en la Península. Por otro lado, los indicios que sugieren que Sisebuto quiso vincularse a la familia que logró la unificación territorial y religiosa, la misma a la que Juan de Biclaro elogia y cuyos actos oscuros escamotea.

Isidoro presentó a Sisebuto en su primera redacción de la Crónica como el nuevo Leovigildo, por sus conquistas, y como el nuevo Recaredo, por su celo religioso ${ }^{123}$. La Crónica de Juan de Biclaro estaría evidentemente acorde con el discurso que subyace a esta imagen de Sisebuto. Las menciones de algunas personalidades ilustres de la Iglesia hispana están dirigidas, creemos, a reconocer el papel que jugaron en la lucha contra el arrianismo y en la definitiva conversión ${ }^{124}$. Por otro lado, el Biclarense ensalza la obra de los miembros de la familia recarediana: Leovigildo habría logrado la unificación territorial y Recaredo la religiosa, mientras que Hermenegildo habría sido una víctima de la arriana Gosvinta. De igual modo, no es casual que el hijo y sucesor de Sisebuto se llamase Recaredo. En los dos únicos antecedentes de tal práctica en el reino de Toledo,

119 Cardelle, Victoris Tunnunensis, pp. 131*-132*.

120 Hunc alii morbo, alii ueneno asserunt interfectum (IsId. Hisp., Hist. Goth., 61; Rodríguez Alonso, C. (ed.). Las Historias de los godos, vándalos y suevos de Isidoro de Sevilla. León, 1975). Sobre los problemas políticos previos al acceso al trono de Suintila véase García Moreno, L. A. «La oposición de Suintila: iglesia, monarquía y nobleza en el reino visigodo». En Ladero, M. Á.; Álvarez, V. Á. y Valdeón, J. (eds.). Estudios de Historia Medieval. Homenaje a Luis Suárez. Valladolid, 1991, pp. 193-208.

121 Así lo cree Martín, J. C. «La "Crónica Universal” de Isidoro de Sevilla: circunstancias históricas e ideológicas de su composición y traducción de la misma». Iberia: Revista de la Antigüedad, 2001, vol. 4, p. 202.

122 Idea que ya señaló Hillgarth, «Historiography», p. 273.

123 Martín, "La "Crónica Universal”", n. 16.

124 Es de sobra conocido el papel de Leandro de Sevilla, Masona de Mérida o el abad servitano Eutropio. El Biclarense también cita al abad servitano Donato, al presbítero de Mérida Juan y a los obispos Domnino de Elna y Novelo de Complutum (Iohan. Bicl., Chron., 18, 22, 30, 51, 55 y 77). 
se asociaba el proyecto político paterno con el del homónimo de su hijo: Hermenegildo lo llamó Atanagildo, igual que el bisabuelo materno de la criatura, mientras que Recaredo escogió el de su tío Liuva.

La actuación religiosa y militar de Sisebuto también está en consonancia con el contenido de la Crónica. Si en época de Leovigildo y Recaredo se logra la supremacía respecto al Imperio y se extirpa el arrianismo, entre los objetivos de Sisebuto estaba acabar definitivamente con las herejías y con la presencia imperial en Hispania. Desaparecido el arrianismo, el judaísmo jugó el papel de antagonista en el campo religioso. Los reyes visigodos gobernaban sobre una sociedad cristiana perfecta en la que la religión hebrea aparecía como el único obstáculo para la definitiva consolidación del reino como Respublica christiana ${ }^{125}$. Sisebuto desarrolló una política de conversiones forzosas que, sin ser del agrado de Isidoro de Sevilla, fue finalmente asumida por la Iglesia visigoda.

En cuanto a la provincia bizantina, pocas dudas hay de que entre los planes de Sisebuto entraba su conquista. De hecho, Isidoro dice que venció a los romanos capturando algunas de sus ciudades ${ }^{126}$, y si bien es cierto que finalmente no fue él quien acabó expulsando a los imperiales, la empresa parecía bien encarrilada para que la culminara su sucesor. Tan es así, que, pese a sufrir al mismo tiempo dificultades internas, Suintila sólo necesitó cuatro años para redondear la hazaña. No extraña que en este contexto la Crónica del Biclarense se caracterice por la exaltación del reino visigodo frente al Imperio, lo que también constituye una idea directriz de la obra de Isidoro de Sevilla ${ }^{127}$. Es más, en lo relativo a la Península, se puede observar que las dos primeras noticias del reinado de Leovigildo, tras la célebre síntesis de su reinado -provinciam Gothorum (...) mirabiliter ad pristinos revocat terminos- corresponden a combates victoriosos con los bizantinos.

En fin, en los escritos de Sisebuto se percibe una animadversión hacia la familia de Atanagildo que no desentona con la Crónica del Biclarense. La obra literaria del monarca estuvo animada por la afirmación de la ideología católica del reino ${ }^{128}$. En su Vita Desiderii responsabiliza de la muerte de San Desiderio a Brunequilda y a su hijo Teoderico II, hija y nieto respectivamente de Gosvinta y Atanagildo ${ }^{129}$. Probablemente tenga esto que ver con que buscaba mantener relaciones cordiales con Clotario II, quien había reunificado todos los reinos francos y había sido rival de los monarcas a los que Sisebuto vitupera. En el ámbito interno quizás pretendía así desligarse definitivamente de la familia de Atanagildo que, según las fuentes posteriores al III Concilio de Toledo, tan solo había traído problemas al reino visigodo: fue Atanagildo quien pidió ayuda a los imperiales a los

125 Beltrán, F. M. «Siervos del Anticristo (la creación del mito histórico del enemigo interno en las fuentes hispanovisigodas)». En Iglesia, J. I. de la (coord.). Memoria, mito y realidad en la historia medieval. XIII Semana de Estudios Medievales, Nájera, del 29 de julio al 2 de agosto de 2002. Logroño, 2003, pp. 85-127.

126 Isid. Hisp., Hist. Goth., 61.

127 Martín, "La "Crónica Universal”», p. 201. Aunque el Biclarense no muestra hacia el Imperio la hostilidad de Isidoro.

128 Fontaine, J. «King Sisebut's Vita Desiderii and the Political Function of Visigothic Hagiography». En James, E. (ed.). Visigothic Spain: new approaches. Oxford, 1980, pp. 93-129.

129 Martín, J. C. "Verdad histórica y verdad hagiográfica en la Vita Desiderii de Sisebuto». Habis, 1998, vol. 29, pp. 291-301. 
MIKEL POZO FLORES

que ahora había que combatir; a Gosvinta se le atribuye la responsabilidad de la rebelión de Hermenegildo; Brunequilda había ofendido al reino al no permitir el matrimonio entre Ermenberga, hija de Viterico, y Teodorico II.

\section{Conclusiones}

En el tratamiento de las fuentes, Juan de Biclaro no deja de lado su formación como historiador: la pone al servicio de un discurso político-religioso que la investigación de las últimas décadas ha puesto en evidencia. No solo no hay una primacía de los testimonios orales y los recuerdos personales, sino que maneja fuentes griegas, anteriores y posteriores a su estancia en Constantinopla, con notable eficacia: los acontecimientos son cuidadosamente escogidos y, si es preciso, desmontados y descontextualizados para insertarlos en la sofisticada construcción de su Crónica.

Asimismo, toda una serie de indicios formales, de contenido y de estructura apuntan al conocimiento y uso de las Historias de Gregorio de Tours por Juan de Biclaro. Claro está, no como fuente primaria de acontecimientos que Juan conocía sin duda mucho más de cerca, sino como obra de referencia con la que Juan intenta dialogar y a la que opone una alternativa para la lectura de la rebelión católica de Hermenegildo. Esta perspectiva permite explicar algunos de los problemas que ha suscitado la interpretación de este conflicto, como el papel de Gosvinta, en función de la lógica interna de la Crónica misma.

En fin, en coherencia con los resultados de esta aproximación al uso de las fuentes y con el estado actual de las investigaciones, conviene considerar un arco cronológico más amplio para la composición y publicación de la Crónica. Hay razones para, cuando menos, contemplar la posibilidad de una publicación bajo el reinado de Sisebuto, es decir, más cerca de Isidoro que de Leovigildo. 